\title{
Editorial:
}

\section{Teaching and Teacher Education Research in Canada}

\author{
Darlene Ciuffetelli Parker and Julian Kitchen \\ Editors \\ Brock University
}

Recently, at a symposium in Toronto, it was refreshing to hear that educators are taking seriously Canadian-based research on teaching and teacher education. Indeed, there is rich and meaningful research being conducted right in our own backyard by a multitude of scholars and practitioners, well known in our communities and developing names for themselves internationally. As the editors of Brock Education, we want to highlight Canadian studies (whether supported or not by granting agencies) that can help enhance our schools and educational communities, while contributing to research locally, provincially, nationally, and internationally. This issue showcases some of that important work.

We begin with Kitchen's article, "Advancing Teacher Education through Faculty Development." Teacher education is critical to the development of teachers able to meet the learning needs of students in an increasingly complex and diverse society. Kitchen identifies key themes in teacher education since the 1980 's and some of the challenges to the professionalization of clinical faculty and professors of education. He argues that teacher education is a specialized field of scholarship and, therefore, the preparation of teacher educators needs to become more rigorous and systematic. He encourages deans of education to make faculty development a critical component of teacher education reform.

To illustrate how professional development is useful for teacher researchers, we offer our readers the peer work of Figg, Wenrick, Youker, Heilman, and Schneider. The article examines how five teacher researchers functioned successfully as a network of "critical friends" over a number of years during the duration of their dissertation work, which they term a peer debriefing team. They illustrate how a successful peer debriefing team is one where team members demonstrate a commitment to the group, continuity and consistency in attending meetings, and an interest in assuring that individual members of the team meet their identified learning goals. Although the team members have dispersed to other universities and work places, they continue to use what they learned from this group in order to offer quality feedback, objective critique and trusted relational networking that encourages, validates and fosters further research productivity.

McIntosh's article, which examines five novice intermediate Language Arts teachers working in Ontario classrooms, also highlights the importance of collaboration. The teachers recently 
graduated from a northern Ontario faculty of education where McIntosh introduced and incorporated the instructional literacy strategy of reading response journals in her English methods course. The study examines how theory studied in a teacher education program was utilized with success in the 'real world' of teaching, beyond McIntosh's methods course in the teacher education program. McIntosh's experience in doing this research allowed her to realize the critical component of reflective practice in teaching, and the time needed for such reflection to occur. Her research illustrates the importance for tracking novice teachers in their early career stages, in order to provide meaningful information for both in-service teaching and for continued success of pre-service education courses.

Next, Elliott-Johns and Booth provide a comprehensive international literature review on the topic of boys' literacy development and move their theory into examples of practice both in and outside Canada. Their article digs deeply into the debate about the achievement of boys' and girls' literacy. Six examples of related collaborative classroom research projects offer ideas for how educators and researchers are working in tandem to support students' literacy learning, in particular the area of boys' literacy. Important in this article is the inquiry site-based model exemplified, as well as additional suggestions for readings and resources that can be utilized by program organizers.

Effective teachers are able to adapt pedagogy and curriculum to the needs of students. In "Besoins perçus et adaptation des démarches d'enseignement: le cas de l'enseignement des sciences et technologies au secondaire"-in English, the title is "Perceived needs and the adjustment of teaching approaches: the case of science and technology teaching in secondary schools"- Sylvie Houde and Jean-Claude Kalubi study the dynamics of how teachers adapt their approaches. Through focus groups, they identify a multiplicity of ways that science and technology teachers make adjustments. The authors respect and celebrate teachers as professionals able to plan curriculum in complex ways. At the same time, they call for teaching approaches that better suit student needs.

Stories have the power to touch us and change our understanding of ourselves, others, and the world in which we live. Teacher Man, recounts distinguished author Frank McCourt's experiences as an idiosyncratic and passionate teacher in New York. Renate Schulz, in a graduate course for teachers, used this book to stimulate teachers to reflect on practice, write their own stories, and examine connections between theory and practice. Schulz, in "Frank McCourt's Teacher Man: A Novel Approach to Teacher Learning and Professional Development," adopted an inquiry stance by explicitly studying the impact of this approach. This study concludes with ways in which reading stories of teaching can prompt educators to write their own stories and, by doing so, better understand their own practice.

We hope you enjoy this issue, which reflects the kinds of teacher inquiry research happening between the spaces and places of classrooms and universities. We hope this issue may motivate you to engage in inquiry in your educational context and, if so, consider submitting your research to Brock Education Journal. 